\title{
The fiscal smile - On the effectiveness and limits of fiscal stabilizers
}

\author{
Jesús Crespo Cuaresma* Gerhard Reitschuler ${ }^{\dagger}$ \\ Maria Antoinette Silgoner ${ }^{\ddagger}$
}

June 4, 2003

\begin{abstract}
The smoothing impact of fiscal stabilizers (proxied by government expenditures) on business cycle volatility is studied for a panel of EU countries in the period 1970-1999. Special emphasis is put on the investigation of possible nonlinearities in the relationship between GDP growth volatility and fiscal stabilizers. The results show that the business cycle volatility smoothing effect of fiscal stabilizers may revert at high levels. The results hold when using government revenues as a proxy for fiscal stabilizers.
\end{abstract}

JEL classification: E62, E63, C23

Keywords: Fiscal Stabilizers, Business Cycle Volatility, Nonlinearity.

*Jesús Crespo Cuaresma, Department of Economics, University of Vienna, Bruennerstr. 72, A 1210 Vienna, Austria, Phone (+43 1) 4277374 77, Fax: (+43 1) 4277374 98, E-mail address: jesus.crespo-cuaresma@univie.ac.at

${ }^{\dagger}$ Gerhard Reitschuler, Oesterreichische Nationalbank, Foreign Research Division, OttoWagner-Platz 3, POB 61, A-1011 Vienna, Austria, Phone (+43 1) 40420 5233, Fax: (+43 1) 40420 5299, E-mail address: gerhard.reitschuler@oenb.at

${ }_{\ddagger}^{\ddagger}$ Maria Antoinette Silgoner, Oesterreichische Nationalbank, Foreign Research Division, Otto-Wagner-Platz 3, POB 61, A-1011 Vienna, Austria, Phone (+43 1) 40420 5231, Fax: (+43 1) 40420 5299, E-mail address: maria.silgoner@oenb.at 


\section{Introduction}

Fiscal policy, according to a typical textbook definition has three broad functions: allocation, distribution and stabilization. Allocation policies deal with those activities in which it is believed, on practical or theoretical grounds, that government may allocate resources more efficiently than markets. The distribution function involves a reallocation of resources on the assumption that the market operates but produces less desirable outcomes than socially acceptable. The most obvious method of redistribution is through the income taxation system and through varied rates of indirect taxation.

The third main goal of fiscal policy is the stabilization of business cycle fluctuations. The usual underlying argument is that output volatility has a negative impact on long-term growth. ${ }^{1}$ This assumption is inspired by several theoretical underpinnings: A first argument is related to skill losses due to temporary unemployment during recessions with negative consequences on productivity and long-term growth (Martin and Rogers, 1997). A second line of argumentation rests on the observation that growth is usually low in periods of political instability. Hence, an increase in political uncertainty as a consequence of high business cycle volatility may depress the prospects for medium-term growth (Alesina et al., 1992). Another argument refers to credit-market imperfections that may force firms to cut their expenditure on research and development during downswings as banks usually do not accept human capital as collateral (Stiglitz, 1994). The most common argument stresses the importance of uncertainty for investment: If investment decisions are irreversible, it may be rational for firms to postpone them in times of uncertainty. To the extent that high business cycle fluctuations increase the uncertainty about the future prospects of the economy, the theory predicts a negative relationship between cyclical volatility and longrun growth via lower investment (Dixit and Pindyck, 1994). ${ }^{2}$

The stabilization of business cycle fluctuations through fiscal policy measures can work through (at least) three different channels. The first channel refers to the most typical stabilization effect of fiscal policy: the role of automatic stabilizers. Theoretically, automatic stabilizers smoothen economic activity through the automatic response via taxes and the transfer system: In recessions fewer (personal income and corporate) taxes are collected and more unemployment

\footnotetext{
${ }^{1}$ For empirical evidence concerning the negative impact of cyclical volatility on growth see, e.g., Ramey and Ramey (1995).

${ }^{2}$ There are, however, arguments in favor of a positive impact of business cycle volatility on long-term growth, others that point at the independence of the two phenomena and studies that even show a reverse causality. For a detailed overview on all the theoretical arguments supporting these different hypotheses as well as empirical evidence see, e.g. Döpke (2002).

Despite the mixed empirical evidence on the relationship between long-term growth and business cycle volatility there seems to be consensus that the stabilization of medium-run fluctuation is a good by itself. An extra argument refers to the welfare losses due to underused capacities.
} 
benefits are paid, ${ }^{3}$ which both support incomes. Vice versa, during a boom the increase in government revenues from taxes and the reduction of transfer payments counteracts the expansion in aggregate demand. These kind of taxes and transfers react automatically to changes in the economic situation and can therefore be regarded as direct fiscal stabilizers. ${ }^{4}$

There is, however, a second, indirect stabilizing channel of fiscal policy that is related to government expenditures that remain fixed in size independent of the stage of the cycle. By not responding to the cyclical condition of the economy they indirectly have a stabilizing function, too. The third channel through which fiscal policy can - at least in principle - have a stabilizing effect on the business cycle is the use of discretionary fiscal policy measures. Even if there is some empirical evidence for a stabilizing effect of discretionary measures (see, e.g., Van den Noord, 2000), the majority of the papers point at a pro-cyclical bias of these measures and therefore at a destabilizing effect, a view also taken by international institutions.

Of these three stabilizing effects the automatic stabilizers are certainly the ones that are most relevant for the current debate on the optimal role of fiscal policy. The discussion on the effectiveness of automatic stabilizers has become more intense since the start of the introduction of the Maastricht criteria and the Stability and Convergence Programmes. The goal set out in the Stability Programs implied that countries should reach a budgetary position 'close to balance or in surplus' in order to be capable of letting automatic stabilizers play fully and symmetrically over the business cycle and at the same time not breach the $3 \%$-deficit criterion of the Maastricht treaty.

The recommendation to let automatic stabilizers fully play can be found in many official documents of international institutions such as the OECD, the IMF or the European Commission. They are typically of the following form: 'maintaining a medium-term policy focus with symmetrical use of automatic stabilizers is essential for non-inflationary growth', 'importance of letting automatic stabilizers work (both on the revenue and expenditure side)' or 'restrict the use of discretionary budgetary policy in order not to offset the built-in mechanism of automatic stabilizers' (see, e.g., OECD, 2001, Heller, 2002, European Commission, 2001). Obviously there seems to be consensus in these international institutions that automatic stabilizers are effective in stabilizing the business cycle, provided that their working is not offset by discretionary fiscal policy.

\footnotetext{
${ }^{3}$ This stabilizing property is evidently stronger if the tax system is more progressive and if the unemployment benefit system is more generous.

${ }^{4}$ Even though the effect of those fiscal measures that work as automatic stabilizers on GDP growth variability is desirable for policy makers, they are in many cases not explicitly implemented to smoothen business cycle fluctuations, but are a by-product of actions targeted at other fiscal policy goals. In many cases the measures are primarily chosen under equity or redistribution aspects.
} 
Empirically there are three broad categories of contributions dealing with the issue of the effectiveness of fiscal stabilizers, some of them focusing on the expenditure side, some of them on the revenue side of the budget. Most international institutions use their large-scale macro-models to estimate the elasticity of tax revenues or public expenditures with respect to changes in output or the output gap. ${ }^{5}$ The second approach is to characterize the response of output to tax and spending shocks in the past by means of structural vector autoregressive models in order to derive impulse-response functions (see, e.g., Blanchard and Perotti, 1998). Finally, Fatás and Mihov (2001a, 2001b) test the correlation between government size and output growth volatility within cross country as well as panel data studies. They find a strong and robust negative relationship both for OECD countries and across US states. Summing up, the evidence form these various empirical studies suggests that fiscal stabilizers are indeed effective in reducing output variability.

This paper re-assesses empirically the smoothing impact of fiscal stabilizers using a panel of EU countries. Our model setting partly builds on earlier work by Ramey and Ramey (1995) and Fatás and Mihov (2001a, 2001b). However, it extends it in several ways. First of all, while earlier work is mostly based on cross sectional data and uses panel data only for selected aspects, our paper relies entirely on pooled estimation. Second, we use an extended set of economic and political variables that so far has not been used in this context.

We initially test the effectiveness of fiscal stabilizers within a linear framework but then take one step further: Are fiscal stabilizers subject to diminishing returns? Is there a threshold level beyond which their stabilizing effect might even revert? The hypothesis of a reversed effect for higher levels of fiscal stabilizers is certainly a new and strong notion in this context. But even if the smoothing impact might not be reversed, it seems evident that the effect of fiscal stabilizers on business cycle fluctuations could level out at a higher rate than the one implied by applying logs to the explanatory variable, accounting thus for decreasing returns to smoothing.

Allowing for a nonlinear effect sheds new light on the characteristics of fiscal stabilizers, as well as on the quantification and nature of the link between government size and cyclical volatility. While a related nonlinearity hypothesis, namely that government size could have a negative growth impact when it exceeds a certain threshold level, has been frequently formulated in studies (see, e.g. Barro, 1990, Slemrod, 1995), this is the first paper, to the knowledge of the authors, which addresses this issue in the context of fiscal stabilizers.

\footnotetext{
${ }^{5}$ See, e.g., Van den Noord (2000), using the OECD-INTERLINK model, or Barrell and Pina (2003), using the NiGEM model. Brunila et al. (2002), using the EC-QUEST model, find that automatic stabilizers are a powerful tool in the case of shocks to private consumption. They are, however, less effective in the case of shocks to investment and external demand. In the case of permanent supply side shocks they are largely ineffective and may delay structural adjustment.
} 
The paper is organized as follows. Section 2 investigates the impact of fiscal stabilizers on business cycle volatility within a linear framework where we also explicitly consider the potential endogeneity between the variables by performing instrumental variable estimation. Section 3 then investigates the possibility of nonlinearities in the relationship between fiscal stabilizers and business cycle volatility. Section 4 applies the same methodology to the different subcomponents of government expenditures and revenues to examine which of these components can most directly be related to the stabilizing aspect of fiscal policy. Section 5 concludes. Details about the data and certain aspects of the econometric specification can be found in the appendix.

\section{Do fiscal stabilizers indeed stabilize? - A first approach}

This section starts with some clarifications on our proxy for fiscal stabilizers. After a very basic investigation of the effectiveness of fiscal stabilizers we then examine the issue in an extended linear model setting.

In a very first step we want to get an impression of the interaction between fiscal stabilizers and the volatility of output growth. Our basic data set consists of yearly data on $14 \mathrm{EU}$ countries covering the period 1970 to $1999{ }^{6}$

\subsection{Fiscal policy: Fiscal stabilizers and discretionary pol- icy}

The first problem that arises is the definition of an appropriate proxy for fiscal stabilizers. We will focus on the most general measure: the average ratio of government spending to GDP. Obviously the automatic component of fiscal stabilizers does not only work from the expenditure side (unemployment benefits and other transfer payments), but also from the revenue side, mainly through personal income and corporate taxes. However, there seems to be no clear consensus in the empirical literature on which side of the government budget is more appropriate when investigating the impact of fiscal stabilizers: Van den Noord (2000) and Fatás and Mihov (2001a) for instance, argue on the importance of the government expenditure side, while the European Commission (2002) - although in a slightly different context - refers to the revenue side as being the one that is more influenced by the business cycle.

\footnotetext{
${ }^{6}$ Our data set contains all current EU countries with the only exception of Luxembourg. For some countries the time range is shorter so that the sample is not balanced.
} 
Our decision to concentrate our analysis on aggregate government spending should be seen in the light of the discussion on the various channels of fiscal stabilization as referred to in the introduction. By focusing on the expenditure side we do not only capture the direct effect of automatic stabilizers but also the indirect impact of government expenditures that remain fixed in size irrespective of the stage of the business cycle. This allows a more complete analysis of the issue of the effectiveness of stabilization policies. As a robustness check we will, however, also present evidence on the smoothing properties of public revenues and, more specifically, direct taxes.

The use of the original, unadjusted government expenditure series as a proxy for fiscal stabilizers is common within this strand of literature. We do, however, believe that this approach is not without criticism. Government spending does not only capture a reactive component, that can be related to the automatic stabilization function, and the part of expenditures that is stable irrespective of the stage of the cycle, but also a third, autonomous component of spending that reflects discretionary fiscal policy measures. Empirical evidence for a negative relationship between government size and output growth fluctuations could thus, among other reasons, be due to discretionary policy measures. We will therefore focus our analysis only on the part of government expenditures that is left after filtering out discretionary policy measures.

In the literature there are several approaches to extracting the stabilizing component of government expenditure. One option is to look at the subcomponents of government spending or revenues that can be related more directly to the automatic stabilizing function. Another approach is the one adopted by the IMF and the OECD. Here a 'cyclically adjusted' fiscal balance is constructed by relating the budget deficit to the state of the cycle relative to a cyclical indicator (for example the output gap).

The approach of this paper is a different one. We estimate an unobserved components model following Harvey $(1985,1989)$ in order to separate a trend, a cyclical component and an irregular part of the government expenditure ratio series. The irregular part is then assumed to represent discretionary fiscal policy measures and is subtracted from the data. The remaining part constitutes a better measure for the fiscal stabilizers. ${ }^{7}$ For the rest of the paper we will refer to it as adjusted government expenditure. ${ }^{8}$

\footnotetext{
${ }^{7}$ There is, however, some empirical evidence pointing at a counter-cyclical effect of discretionary fiscal policy (see, e.g., Van den Noord, 2000). In such a case our filtering approach is likely to catch only a part of discretionary measures. As the purpose of our study is, however, to shed light on the effectiveness of stabilization polices that can work through the three described channels, this adjustment seems appropriate.

${ }^{8}$ For details on the adjustment technique see the appendix. The results presented in the remaining sections appear robust to the filtering procedure. A bivariate unobserved components model with government spending share and logged GDP was also used for the adjustment in order to refine the extraction of the irregular component. The results remained qualitatively and quantitatively similar and are available from the authors upon request.
} 


\subsection{Do fiscal stabilizers reduce business cycle volatility?}

To get a first visual impression of the nature of the relationship between government size and output growth volatility we divide our data set into 6 subperiods (1970-74, 1975-79, 1980-84, 1985-89, 1990-94, 1995-99). ${ }^{9}$ Figure 1 shows a scatter plot that relates GDP growth volatility to the size of the government measured by logged adjusted government expenditures. By first eyeball inspection, a negative relationship between these two variables seems to prevail.

The following baseline regression is estimated to establish the effect of fiscal stabilizers on output growth volatility:

$$
\text { VOLGROWTH } H_{i t}=\beta\left(G O V E X P_{i t}\right)+u_{i t},
$$

where the left hand variable is the standard deviation ${ }^{10}$ of output growth in period $t(t=1, \ldots, 6$ stands for each of the subperiods described above) for country $i$ and GOVEXP $P_{i t}$ is the logged ratio of government expenditures over GDP, adjusted for the irregular component.

The regression results for equation (1) - based on different assumptions for the error term - are presented in Table 1 . The first column shows the result for the assumption that the error term is independent of the cross-sectional units (countries) and iid normal (that is, the panel is estimated as if it were a crosscountry regression including a constant). The second column shows the results for the assumption of fixed country effects, that is,

$$
u_{i t}=\alpha_{i}+\varepsilon_{t},
$$

where $\alpha_{i}$ is a country-specific constant and $\varepsilon_{t}$ is white noise. Finally, the third column shows the estimated $\beta$ under the assumption of fixed country and time effects, that is,

$$
u_{i t}=\alpha_{i}+\delta_{t}+\varepsilon_{i t},
$$

\footnotetext{
${ }^{9}$ The choice of five year averages reflects the trade-off between two contrasting arguments. On the one hand we need a subperiod size that allows for reasonable measures of output growth volatility. On the other hand we explicitly want to focus on short to medium term developments so that our subperiod length should not exceed the average duration of the business cycle. In the literature the estimates for the business cycle length in European countries deviate substantially across countries and depending on the detrending method. In general, however they remain within a range of around 3 to 5 years, so that our five year averages seem justified. For recent estimations on the euro area as well as on selected European countries see, e.g., Harding and Pagan (2001) or Artis et al. (2003).

${ }^{10}$ The most obvious measure for the volatility of output growth would be the variation coefficient, where the standard deviation is divided by the average growth rate to make the measure scale independent. There are, however, subperiods where the average growth rate is almost zero so that the variation coefficient takes huge values. This is why we chose the standard deviation instead as a measure for output growth volatility. The same comment applies also to inflation volatility that is used in a later step of the paper.
} 
where $\alpha_{i}$ and $\varepsilon_{t}$ are defined as above, and $\delta_{t}$ is an exclusively time-dependent constant effect.

All specifications reported in Table 1 show a negative coefficient $\beta$, and the coefficient is highly significant for the more general models (2) and (3). The results therefore seem to confirm that fiscal stabilizers have had a smoothing impact on the business cycle. ${ }^{11}$

\subsection{Introduction of controls}

The results of the previous section suggest a negative relationship between government size and the volatility of output. Still, there might be additional variables that affect both volatility and government size: In other words, the results obtained so far could only represent an indirect link between volatility and government size. We thus add several variables to our baseline regression to control for this possibility.

Table 2 shows the results of the panel regression using as controls the unemployment rate, inflation volatility and GDP per capita. The main argument for the first control variable is that in times of weak economic performance a low unemployment rate $\left(U N E M P L_{i t}\right)$ makes employers reluctant to dismiss workers as it might prove hard to find a worker of appropriate qualifications after economic activity has recovered. A low unemployment rate is thus likely to constitute a smoothing factor for the business cycle implying a positive relationship between the unemployment rate and GDP growth volatility. Our second control variable, inflation volatility $\left(V O L I N F L_{i t}\right)$ - measured by the standard deviation of the inflation rate - is included as an indicator for monetary policy that certainly interacts with GDP growth volatility. Logged real GDP per capita $\left(G D P p c_{i t}\right)$ finally is added as a control based on the assumption that richer economies usually do not only have a more sophisticated system to counterbalance economic shocks but also a more developed financial system.

The new specification is thus:

$$
\begin{aligned}
\text { VOLGROWTH } H_{i t}= & \beta_{1}\left(G O V E X P_{i t}\right)+\beta_{2}\left(U N E M P L_{i t}\right)+ \\
& \beta_{3}\left(\text { VOLINFL L } L_{i t}\right)+\beta_{4}\left(G D P p c_{i t}\right)+u_{i t}
\end{aligned}
$$

We also include time dummies as well as an additional dummy variable that accounts for the German unification. The negative and significant coefficient for government size confirms our previous results, pointing at the effectiveness of the fiscal stabilizers. The coefficients for unemployment and the inflation volatility display the expected positive signs and are highly significant. The coefficient for GDP per capita also appears significant albeit positive, suggesting

\footnotetext{
${ }^{11}$ These results are robust to the exclusion of potential outliers.
} 
that richer countries actually experienced more volatile business cycles. ${ }^{12}$

\subsection{Accounting for the potential endogeneity of fiscal sta- bilizers}

The problem with equation (4) is the potential endogeneity of government size. Rodrik (1998) comments that as long as one of the goals of governments is to reduce output growth volatility, economies that display higher volatility might choose larger governments to stabilize their cycles. In this case equation (4) would be subject to an endogeneity problem and OLS estimation could lead to biased results.

To account for endogeneity we need to find instruments for government size. A straightforward way to search for appropriate instruments is to estimate the following equation:

$$
G O V E X P_{i t}=\sum_{j=1}^{K} \beta_{j} X_{j, i t}+u_{i t}
$$

where $X_{i t}$ is a set of $K$ economic and political variables. All variables that display a robust and significant relationship with GOVEXP $P_{i t}$ in this equation but are not correlated with the error term of equation (4) are obvious candidates for instruments. This procedure will also shed light on the determinants of government size in the EU countries.

In a first step, we include four macroeconomic variables in our baseline specification (5): GDP per capita, the unemployment rate, openness and interest payments on public debt. We expect a positive sign of the coefficient for GDP per capita because, according to Wagner's Law, richer countries tend to have larger governments as some public goods are considered to be income elastic. The (partial) correlation between unemployment and government size is also expected to be positive as the unemployment benefits constitute an important fraction of government expenditures. Concerning openness $\left(O P E N_{i t}\right)$, measured as the average sum of exports and imports relative to GDP, Rodrik (1998)

\footnotetext{
${ }^{12}$ As check for robustness we conditioned our regression on several other variables. Openness, measured as the average sum of exports and imports relative to GDP, was included because, as Rodrik (1998) suggests, an economy that displays a higher degree of openness should be capable to better cope with shocks as these tend to counterbalance each other as well as the internal shocks. In this case and as long as the internal and the external shocks are not perfectly correlated, the output growth volatility should be negatively correlated with openness. The fact that the coefficient never turned significant gives evidence that for our European sample internal and external shocks are highly correlated so that the degree of openness does not significantly affect the volatility of growth rates.

Other control variables used in various combinations are population, average inflation levels, volatility as well as average levels of core inflation (excluding energy and certain food categories) and GDP growth. The coefficients never appeared significant and left the other coefficients basically unchanged.
} 
argues that there could be a correlation between an economies' trade exposure and the size of the government as open countries are more subject to external shocks, and therefore choose a larger public sector as a stabilizer. A further explanatory variable that is assumed to have an impact on the government size is a measure for the interest payments on government debt as a percentage of GDP $\left(I N T P A Y_{i t}\right)$. A higher debt level as well as a higher interest rate on government debt should be positively correlated with government expenditures.

In a second step, we add two political variables to the right hand side of equation (5): a government strength indicator and the number of elections. The reason for including these variables as suggested by the literature on the political economy of fiscal policy is that fiscal indicators (as levels of deficit, debt or government expenditures) can only partly be explained by genuine macroeconomic variables, and that political variables such as electoral and political systems also have explanatory power. ${ }^{13}$

The first political variable in our specification is a measure for the strength of the government $\left(S T R E N G T H_{i t}\right)$ vis-à-vis the opposition. In general, each party in parliament has a certain number of opportunities to form coalitions with other parties when it comes to set up a government. That implies that each party has a certain degree of power to make or break a government coalition. Very often, this power is poorly reflected by only looking at the share of seats in parliament of a party. Power can thus be measured more adequately by applying voting power indices to the distribution of seats in parliament. The two most frequently used government power indices are the Shapley-Shubik-Index (Shapley and Shubik, 1954) and the Banzhaf-Index (Banzhaf, 1965). The government strength variable we use is the normalized Banzhaf-Index, defined as the weighted sum of the governing parties' power indices. ${ }^{14}$ It is defined over the unit interval and takes the value of one for a single party majority government whereas coalition governments will in most cases have a value of smaller than one. The so called 'weak government hypothesis' suggests a negative relationship between government strength and fiscal expenditures (see, e.g. Roubini and Sachs, 1989) and it relies on a prisoners dilemma type of problem. Although a general cut of expenditures might be a desirable target for all parties in a coalition, none of the ministers has an incentive to stick to consolidation agreements in his field because this might upset the parties' own voters. Therefore we would expect higher expenditures in coalition governments - the ones with a lower strength index - than in single party governments. ${ }^{15}$

Another political variable that could potentially be of relevance as explanatory variable is the number of legislative and executive elections $\left(E L E C T_{i t}\right)$. The hypothesis is that not only discretionary policy might be driven by the electoral cycle but that also the fiscal stabilizing part of government expenditures

\footnotetext{
${ }^{13}$ See, e.g., Roubini and Sachs (1989), Drazen (2000), Persson and Tabellini (2000).

${ }^{14}$ For more details on the Banzhaf-Index, see the appendix.

${ }^{15}$ In the literature there is, however, no clear cut empirical evidence for this hypothesis.
} 
could be expanded before elections. This would suggest a positive correlation between the number of elections and government expenditures, even when adjusted for the discretionary part.

In a third step we include the size of the economy as a further variable, measured through population $\left(P O P_{i t}\right)$. Alesina and Wacziarg (1997) suggest that the correlation between openness and government size is not a direct one, but that the link is mediated by country size. They show that country size is negatively related to government size as well as to trade openness.

The final specification based on equation (5) is thus:

$$
\begin{aligned}
G O V E X P_{i t}= & \beta_{1}\left(G D P p c_{i t}\right)+\beta_{2}\left(U N E M P L_{i t}\right)+\beta_{3}\left(O P E N_{i t}\right)+ \\
& \beta_{4}\left(I N T P A Y_{i t}\right)+\beta_{5}\left(S T R E N G T H_{i t}\right)+ \\
& \beta_{6}(E L E C T)+\beta_{7}(P O P)+u_{i t}
\end{aligned}
$$

The first column in Table 3 shows the regression results including the four macroeconomic variables mentioned above. All of them appear highly significant. GDP per capita, the unemployment rate and the measure of the interest payments on government debt all enter with the expected positive signs. The negative coefficient of openness, however, seems to contradict the hypothesis of Rodrik (1998). The reason could be that as shocks are highly correlated in Europe there is less demand for large governments as an insurance against external shocks. On the other hand the high degree of synchronization also implies that a small open economy could profit from fiscal measures of their main trading partners aimed at counterbalancing shocks and could therefore free-ride on the stabilizing effects of such measures. A different argument finally suggests that open economies can take over norms form their main trading partner countries, thereby reducing the scope of government expenditures.

The second column shows the results based on the extended set of explanatory variables. STRENGTH $H_{i t}$ enters with a positive sign, indicating that stronger governments were associated with higher government expenditure ratios. Hence our results do not seem to support the weak government hypothesis. ${ }^{16}$ The coefficient for $E L E C T_{i t}$ is positive but not significant. In the third column, the coefficient for the size of the economy enters with the expected negative sign and is significant. The fourth column re-estimates the model without the election variable but without any significant change for the main results.

Based on these results the variables interest payments, openness, government strength and population are the obvious candidates as instruments in equation (4). The results of the re-estimation of equation (4) using instrumental variables are presented in Table 4. The Sargan test for the validity of instruments

\footnotetext{
${ }^{16}$ One has to note, however, that the literature on the weak government hypothesis mainly uses deficits instead of government expenditures as explanatory variable.
} 
takes a value of 8.7 , so we cannot reject the null of no correlation between the instruments and the errors in equation (4).

Even though the coefficient for government size is still negative, it is not significant any longer. This result weakens prior empirical evidence, namely that fiscal stabilizers have reduced output volatility. However, it could also be an indication for omitted nonlinearities in the relationship between government size and economic volatility. We will take explicit account for that possibility in the following section.

\section{A nonlinear effect of fiscal stabilizers?}

The results of the previous section provide no clear cut picture concerning the smoothing capacity of fiscal stabilizers. Can we infer that the evidence obtained so far is a consequence of nonlinearities that have not been explicitly modeled? The linear model already gives evidence for diminishing returns to the stabilizing property of government spending. We could, however, hypothesize that the effectiveness of this fiscal policy tool is subject to extra diminishing returns that go beyond the ones already implied by the use of the logarithm of government expenditures, possibly even reverting beyond a certain threshold. If such nonlinearities exist, the conclusion of a smoothing impact of fiscal stabilizers of previous studies may not hold for all levels of government expenditures but has to be investigated with reference to the size of the government.

Our hypothesis that nonlinearities as outlined above might exist is partly based on the literature that deals with growth effects of fiscal policy. Here theoretical results (see, e.g., Barro, 1990) predict a negative growth effect in countries where the size of government exceeds a certain threshold. Under the assumption that there is a robust negative correlation between volatility of output and long term growth, the resulting inverse U-shaped relationship between government size and growth would translate into a U-shaped relationship between government expenditures and cyclical output volatility. Higher levels of public spending are furthermore associated with either higher taxes or larger budget deficits. The adverse effects of high tax burden on production are related to disincentive effects and market distortions, high deficit levels will at some point create an environment of uncertainty due to the loss of credibility of fiscal policy (see, e.g. Giavazzi et al., 2000 and Perotti, 1997). Both of these effects could, in due course, lead to higher output growth volatility.

A initial indication of the presence of nonlinearities can be drawn from Figure 2 that shows the residuals of equation (4), estimated under the restriction $\beta_{1}=0$ (that is the part of GDP growth volatility that cannot be explained by the right hand side variables other than GOVEXP $P_{i t}$ in equation (4)) against the fitted levels of government expenditures over GDP using the instruments and 
exogenous variables. This is the variable actually used instead of GOVEX $P_{i t}$ for the instrumental variables estimation. The visible parabolic relationship suggests to test the nonlinearity hypothesis more thoroughly.

As a very first attempt to examine empirically the evidence for nonlinearities in the relationship between business cycle volatility and government size we apply the linearity test proposed by Hansen (1999). We test the linear model against a piecewise linear model where the effect of government expenditure on growth volatility depends on the level of government expenditure, and explicitly estimate the threshold level of government expenditures separating the two regimes. Although the methodology in Hansen (1999) does not account for instrumental variable estimation, it could provide first evidence for nonlinearities in the relationship. The threshold estimation procedure identifies exactly one threshold at a (logged) government expenditure ratio of 3.67, and rejects the null of linearity at the usual $5 \%$ significance level. For government size levels below the threshold there is a significant negative relationship between the government expenditure ratio and GDP growth volatility, providing evidence for the effectiveness of fiscal stabilizers in this range. Beyond the threshold level, however, the coefficient is negative but not significant, indicating that the smoothing effect of fiscal stabilizers does not apply in this region.

This first evidence opens the question of the specific nonlinear form to be tested. Here a useful econometric tool is the Nearest Neighbor Fit method (see, e.g., Cleveland, 1993 and 1994). This non-parametric approach fits for each data point in the sample a local linear regression line, weighting the other observations: Data points that are relatively far from the point being evaluated get small weights in the sum of squared residuals, while closer data points get higher weights. The resulting nonlinear curve is presented in Figure 3. The parabolic form suggests a leveling out of the smoothing capacity of fiscal stabilizers with the possibility of a reversed effect beyond the minimum.

Based on this evidence we modify our model by letting the government expenditure ratio enter in a quadratic form. Equation (4) is reformulated as:

$$
\begin{aligned}
\text { VOLGROWTH }_{i t}= & \beta_{1}(\text { GOVEXP } \\
& \beta_{3}(\text { UNEMPL })+\beta_{i t}\left(G O V E X P_{i t}\right)^{2}+ \\
& \beta_{5}\left(\text { GDP }\left(\text { VOINF } c_{i t}\right)+u_{i t}\right)+
\end{aligned}
$$

Table 5 shows the results of the linear model as well as the new model with the quadratic specification. ${ }^{17}$ The coefficient for government size is highly significant for the linear as well as for the quadratic variable, thereby confirming the evidence for nonlinearities. The fitted parabolic curve has its low point at 3.63 (in $\operatorname{logs}$ ) which is corresponding to a government expenditure ratio of

\footnotetext{
${ }^{17}$ The estimation is carried out using the same set of instruments as in equation (4), augmented with the squared instruments. The evidence presented hereafter, however, also holds if the squared instruments are not included and/or if some outlying observations are excluded.
} 
approximately 38 percent, a value close to the one indicated by the threshold technique. ${ }^{18}$

In order to provide an intuition about the magnitudes of this nonlinear effect let us consider the following exercise. For a country displaying a government expenditure ratio corresponding to the median value of the distribution in our panel (40.63\%), an increase of public spending by one percentage point will, ceteris paribus, raise the standard deviation of output growth by 0.02 points. The same increase in government spending for a country situated at the $25 \%$ percentile of the distribution (expenditure ratio: $35.87 \%$ ) will lead to a decrease in business cycle volatility of 0.01 points. A country at the $75 \%$ percentile (spending ratio: $44.14 \%$ ) finally would increase cyclical volatility by 0.04 points when expanding government expenditures by 1 percentage point.

To sum up, our results indicate a nonlinear relationship between government size and output growth volatility. For relatively low levels of the government expenditure ratio fiscal stabilizers have the desired impact in that they reduce business cycle fluctuations. This effect, however, is not without bounds. For higher levels the effect is, at best, not significant, but it might as well reverse. ${ }^{19}$

\section{Towards a narrower definition of government size - which fiscal components stabilize most?}

In the previous sections we have established the link between fiscal stabilizers and output growth volatility. On the one hand, we have found no clear indication of a negative relationship in a linear setting. On the other hand we have provided evidence of nonlinearities in the sense that the effect of fiscal stabilizers on business cycle fluctuations could even reverse for higher levels.

Fiscal stabilizers obviously do not only work from the expenditure side but also from the revenue side. The aim of this section is to analyze the nature of the smoothing effect from the revenue side. Using a disaggregated data set allows us furthermore to investigate which subcomponents of government expenditure or revenue can be most directly related to the stabilizing aspect of fiscal policy

\footnotetext{
${ }^{18}$ One could suspect that the parabolic form is driven solely by outliers. The Nearest Neighbor Fit method, however, allows for explicit outlier adjustment. This is done by iterating the local regressions by adjusting the weights to downweight outlier observations. This procedure is repeated until the curve converges. Following this approach of outlier adjustment the resulting curve looks similar to the one in Figure 3, but shows a flatter slope at the left wing. So if anything it is the stabilizing effect of fiscal stabilizers that is affected by outliers.

${ }^{19}$ One could argue that given the lack of flexibility of labor markets unemployment could also depend upon output growth volatility. The results presented above are, however, robust to endogenizing unemployment rates. The significance of the coefficients of government expenditures in the quadratic specification even increases if potential endogeneity is taken into account. The results are not presented here but are available from the authors upon request.
} 
and whether there is also evidence of nonlinearities for the subcomponents.

We therefore rerun our estimation by first substituting government spending by the overall measure revenues $\left(R E V E N_{i t}\right)$, that is computed as the sum of direct and indirect taxes and social security and other transfers received by the government. We then repeat this procedure using as subcomponents of government expenditures non-wage government consumption (GOVCONSnw $w_{i t}$ ), wage government consumption (GOVCONSw $w_{i t}$ ), government gross investment $\left(I N V E S T_{i t}\right)$, subsidies $\left(S U B S I D_{i t}\right)$ and social security transfers paid by the government $\left(S O C S E C_{i t}\right)$. Furthermore we also use transfers $\left(T R A N S_{i t}\right)$ that is the sum of subsidies, social security transfers and other transfers paid by the government. On the revenue side we look at two subcomponents: direct taxes $\left(T_{\left.A X d i r_{i t}\right)}\right.$ and indirect taxes $\left(T A X i n d i r_{i t}\right)$.

Intuitively the subcomponents on the spending side that are most directly related to the theoretical definition of fiscal stabilizers are social security transfers and subsidies. Investment on the other hand can be expected to consist to a large part of discretionary measures. From the two government consumption measures the wage part might contain a discretionary as well as an fiscal stabilizing part while the non-wage fraction should not be closely related to fiscal stabilizers. On the revenue side indirect taxes do not show the standard attributes of fiscal stabilizers like progressivity so that we expect regression results to deviate substantially from the ones derived in the previous sections. Direct taxes on the other hand should show a high degree of stabilizing properties, possibly also levelling out beyond a certain threshold.

We thus rerun the linear and quadratic regressions (4) and (7) using these different fiscal policy measures as explanatory variables. All fiscal measures are used as logs of the share in GDP and those that are expected to contain a significant discretionary part (INVEST $i t$ and GOVCONSwit) are adjusted following the same approach applied to the government expenditure ratio. In all cases the estimation is done using the same instruments selected for the case of the overall government expenditure measure.

The results of the estimation of equations (4) and (7) for the different subcomponents of government expenditures and revenues are given in Table 6 . The results for total revenues show the same characteristics as those of the government spending ratio: Accounting for the possibility of endogeneity, the coefficient for total revenues is negative but not significant. Using a nonlinear model, however, the coefficients are highly significant for the linear as well as for the quadratic term. Therefore the same implication holds that the smoothing effect of fiscal stabilizers from the revenue side may vanish for higher levels. The fact that a similar result applies to direct taxes while this is not the case for indirect taxes supports the hypothesis that it is personal and corporate income taxes that are most directly related to the theoretical definition of fiscal stabilizers. 
Concerning the subcomponents on the expenditure side there is evidence for nonlinearities only for non-wage government consumption whereas the other components do not show any parabolic relationship. The lack of significance of the coefficients for government gross investment can be interpreted as evidence against the hypothesis of a counter-cyclical effect of discretionary fiscal policy.

The main result is therefore that of those subcomponents that are expected to be most directly related to fiscal stabilizers, only revenues and direct taxes show the hypothesized smoothing impact (for lower levels). This effect, however, reverts for higher levels and could actually increase cyclical volatility. Subsidies and social security transfers, on the other hand, do not have a smoothing impact, neither in the linear nor in the nonlinear model setting.

\section{Conclusion}

The effect of fiscal stabilizers (proxied by the government expenditure share adjusted for discretionary policy) on cyclical volatility is studied for a panel of EU member states in the last three decades. The smoothing impact of fiscal stabilizers is tested within a linear as well as a nonlinear framework. Evidence from the linear model concerning the effectiveness of fiscal stabilizers is mixed. While the basic OLS results confirm the finding of prior empirical studies that fiscal stabilizers have reduced business cycle fluctuations this effect is no longer significant when doing instrumental variable estimation to account for potential endogeneity of government size.

However, the results based on a quadratic nonlinear model setting indicate a smoothing effect for lower levels of government size, but the returns to smoothing diminish in a stronger fashion than the one implied by the logarithmic specification. For countries with a high government expenditure ratio the smoothing effect vanishes and cyclical volatility may thus even rise. The results appear robust to the exclusion of outliers, modifications in the specific non-linear form, the use of a different set of control variables and instruments as well as a generalization of the adjustment mechanism for the government expenditure ratio. On a disaggregated level, we find that the non-wage government consumption, direct taxes and total revenues display the nonlinearity mentioned above, namely a stabilizing property up to an estimated threshold which then eventually reverts. The validity of the main findings on the revenue side strengthens our results against the background of the discussion on which side of the budget to use as a proxy for fiscal stabilizers.

Our results suggest that it may be necessary to reassess the role of the fiscal stabilizers - which are nowadays generally preferred by both international institutions and economists vis-à-vis discretionary fiscal policy - in the nonlinearity context. The preference for a rules-based fiscal policy, notably in Europe, stems 
from the fact that the last three decades were marked by prolonged periods of pro-cyclical fiscal policy. ${ }^{20}$ This asymmetric reaction of fiscal policy to the economic cycle led political institutions to the conclusion that a purely rulesbased fiscal policy (in the same reign as monetary policy) would lead to a better economic outcome in the sense of reduced volatility. Given the negative relationship between government size and cyclical volatility in prior studies, this notion seems justified. However, the nonlinear model setting of our paper reassesses this view in a critical way. The discussion on the effect of fiscal stabilizers and optimal government size may gain realism by taking into account nonlinearities such as the ones modeled in this study.

Coming back to the policy recommendations of international institutions to let fiscal stabilizers play fully, our conclusion is that these assessments should be supplemented by taking into account a second dimension: the absolute level of fiscal stabilizers. One should be aware of the fact that the government size plays a crucial role in determining the nature of the returns to smoothing of fiscal stabilizers. Therefore, although the full operation of fiscal stabilizers could be desirable, their overall extent may have to be reconsidered. Hence we conclude 'let the fiscal stabilizers play, but handle them with care'.

\subsection{Acknowledgments}

We would like to thank Mathias Sutter and Martin Kocher for providing us with data on political variables. Furthermore we would like to thank Helmut Hofer, Lawrence Klein, Walpurga Köhler-Töglhofer, Robert Kunst as well as the participants at the "East-West Conference 2002" of the Oesterreichische Nationalbank in Vienna, at the Workshop of Public Finance at the University of Innsbruck and at internal seminars at the European Central Bank, the Institute for Advanced Studies in Vienna, the Vienna Institute for International Economic Studies and the Oesterreichische Nationalbank the for many helpful comments and discussions.

\section{Appendix}

\subsection{Data sources}

The data concerning government expenditures and revenues are from the OECD Economic Outlook database. Real GDP per capita and GDP growth were computed in 1995 prices using data from the World Development Indicators 2001 (World Bank) except the data for West Germany (1970-91), which were built from the International Financial Statistics (International Monetary Fund). The

\footnotetext{
${ }^{20}$ This development which was mainly due to implementation lags of discretionary fiscal policy measures did not only raise cyclical volatility but also caused high budget deficits. As a consequence policy measures that have been set counter-cyclically may very often work pro-cyclical a posteriori.
} 
openness variable was retrieved from the World Development Indicators 2001 (World Bank) except the data for West Germany (1960-91), which were taken from the Penn World Tables 5.5. The source of data concerning population is the Penn World Tables 5.5. Data on unemployment and inflation were taken from the OECD Main Economic Indicators. The data on political variables are from Huber, Kocher and Sutter (2002).

\subsection{Adjusting for discretionary fiscal policy: a structural time series approach}

In order to isolate the components of government expenditure that fluctuate with economic activity, the yearly time series of government expenditure over GDP for each country in the sample is decomposed into a trend component, a cyclical component and an irregular component in an additive fashion. While the trend component reflects the long-run dynamics of the government expenditure series (which can be accounted for by Wagner's law, for instance), the cyclical component accounts for fluctuations related to the business cycle and the irregular component captures the dynamics which are not explained by the other two components. ${ }^{21}$

In the most general case the variable of interest, the government expenditure share $\left(y_{t}\right)$, is decomposed as follows,

$$
y_{t}=\tau_{t}+\psi_{t}+\theta_{t},
$$

where $\tau_{t}$, the trend component, is assumed to be a random walk with drift, where the drift is itself a random walk,

$$
\begin{aligned}
\tau_{t} & =\mu_{t-1}+\tau_{t-1}+\epsilon_{t} ; \quad \epsilon_{t} \sim \operatorname{NID}\left(0, \sigma_{\epsilon}^{2}\right) \\
\mu_{t} & =\mu_{t-1}+v_{t} ; \quad v_{t} \sim \operatorname{NID}\left(0, \sigma_{v}^{2}\right)
\end{aligned}
$$

The cyclical component, $\psi_{t}$, is specified as a sine-cosine wave with constant cyclical frequency, $\lambda$,

$$
\left(\begin{array}{c}
\psi_{t} \\
\psi_{t}^{*}
\end{array}\right)=\rho\left(\begin{array}{cc}
\cos \lambda & \sin \lambda \\
-\sin \lambda & \cos \lambda
\end{array}\right)\left(\begin{array}{c}
\psi_{t-1} \\
\psi_{t-1}^{*}
\end{array}\right)+\left(\begin{array}{c}
\chi_{t} \\
\chi_{t}^{*}
\end{array}\right) ; \quad\left(\begin{array}{c}
\chi_{t} \\
\chi_{t}^{*}
\end{array}\right) \sim \operatorname{NID}\left(0, \sigma_{\chi}^{2} I\right)
$$

where $\rho \in(0,1), \lambda \in(0, \pi)$ and $\psi_{t}^{*}$ appears by construction. The irregular component, $\theta_{t}$ is assumed to be white noise with constant variance $\sigma_{\theta}^{2}$. The parameters of interest in the decomposition can be estimated by maximum likelihood methods after transforming the original model to state-space form and using Kalman filtering in order to obtain the prediction error decomposition. The adjusted series of government expenditure are then computed as the sum of the smoothed estimates of the trend and cyclical component of each series.

\footnotetext{
${ }^{21}$ For more details on structural time series methods, see e.g. Harvey (1985), Harvey (1989) or Harvey and Jaeger (1993).
} 
Each country was treated independently, and for all cases the restriction $\sigma_{\epsilon}^{2}=0$ was set to the trend specification, as it improved the fit significantly. ${ }^{22}$

\subsection{The Banzhaf index}

Consider a set of players $N=\{1,2, . . i . ., n\}$ where player $i$ has voting weight $w_{i}$. Let $\Omega$ be the set of all possible coalitions $S$ which can be formed out of $N$. A winning coalition $S \subset \Omega$ is characterized by $\sum_{j \in S} w_{j} \geq q$ where $q$ denotes the majority requirement. If a coalition $S$ is a winning coalition, the value $v$ of this coalition is defined as one, since $S$ can determine the outcome of a vote. All losing coalitions are assigned a value $v=0$ accordingly. To determine a player $i$ 's voting power, consider all coalitions where player $i$ has a swing, meaning that player $i$ is crucial for turning a losing coalition into a winning one. Player $i$ has a swing if $\sum_{j \in S /\{i\}} w_{j}<q$ but $\sum_{j \in S /\{i\}} w_{j}+w_{i} \geq q$. From that calculate the absolute or non-normalized Banzhaf-Index $B_{i}^{*}$ as follows:

$$
B_{i}^{*}=\frac{\sum_{S \subset \Omega}[v(S)-v(S /\{i\})]}{2^{n-1}}
$$

The denominator $2^{n-1}$ represents the total number of coalitions including player $i$. The normalized Banzhaf-Index $B_{i}$, which is used in this study, relates the number of swings of player $i$ to the total number of swings of all players, resulting in the formula:

$$
B_{i}=\frac{B_{i}^{*}}{\sum_{j=1}^{n} B_{i}^{*}}=\frac{\sum_{S \subset \Omega}[v(S)-v(S /\{i\})]}{\sum_{j=1}^{n} \sum_{S \subset \Omega}[v(S)-v(S /\{j\})]}
$$

The normalized Banzhaf-Index was computed using data on the distribution of seats in national parliaments and the composition of national governments for the period from 1970 to 1999 (for detailed information see Huber et al., 2003).

\section{References}

[1] Alesina, A., Ozler, S., Roubini, N. and P. Swagel (1996), Political Instability and Economic Growth, Journal of Economic Growth 1, 189-212.

\footnotetext{
${ }^{22}$ Details on the univariate estimations are available from the authors upon request.
} 
[2] Alesina, A. and R. Wacziarg (1997), Openness, Country Size and the Government, NBER Working Paper 6024.

[3] Artis, M., M. Marcellino and T. Proietti (2003), Dating the euro area business cycle, CEPR Discussion Papers 3696.

[4] Banzhaf, J. F. (1965), Weighted Voting Doesn't Work: A Mathematical Analysis, Rutgers Law Review 19, 317-343.

[5] Barrell, R. and A. M. Pina (2003), How important are automatic stabilisers in Europe? A stochastic simulation assessment, Economic Modelling, forthcoming.

[6] Barro, R. J. (1990), Government Spending in a Simple Model of Endogenous Growth, Journal of Political Economy 98, S103-S125.

[7] Blanchard, O. and R. Perotti (1998), An empirical characterization of the dynamic effects of changes in government spending and taxes on output, mimeo.

[8] Brunila, A., M. Buti and J. in't Veld (2002), Fiscal policy in Europe: how effective are automatic stabilisers?, European Economy, Economic Papers 177.

[9] Cleveland, W.S. (1993), Visualizing Data, Hobart Press.

[10] Cleveland, W.S. (1994), The Elements of Graphing Data, Hobart Press.

[11] Dixit, A. K. and R. S. Pindyck, (1994), Investment under Uncertainty. Princeton, Princeton University Press.

[12] Döpke, M. (2002), The Causal Link between Business-Cycle Volatility and Long Growth in OECD Countries, mimeo.

[13] Drazen, A. (2000), Political Economy in Macroeconomics, Princeton, Princeton University Press.

[14] European Commission (2001), Public Finances in EMU, Brussels.

[15] European Commission (2002), Public Finances in EMU, Brussels.

[16] Fatás, A. and I. Mihov (2001a), Government Size and Automatic Stabilizers: International and Intranational Evidence, Journal of International Economics 55, 3-28.

[17] Fatás, A. and I. Mihov (2001b), Fiscal Policy and Business Cycles: An Empirical Investigation, Moneda y Credito 212.

[18] Giavazzi F., T. Jappelli and M. Pagano (2000), Searching for NonKeynesian Effects of Fiscal Policy, European Economic Review 44, 12591289 . 
[19] Hansen, B. (1999), Threshold Effects in Non-Dynamic Panels: Estimation, Testing and Inference, Journal of Econometrics 93, 345-368.

[20] Harding, D. and A. Pagan (2001), Extracting, analysing and using cyclical information, paper presented at the Banca D'Italia - CEPR Conference on Monitoring the Euro Area Business Cycle, Rome 7/8 September 2001.

[21] Harvey, A. C. (1985), Trends and Cycles in Macroeconomic Time Series, Journal of Business and Economic Statistics 3, 216-227.

[22] Harvey, A. C. (1989), Forecasting, Structural Time Series and the Kalman Filter, Cambridge: Cambridge University Press.

[23] Harvey, A. C. and A. Jaeger (1993), Detrending, Stylized Facts and the Business Cycle, Journal of Applied Econometrics 8, 231-247.

[24] Heller, P. S. (2002), Considering the IMF's Perspective on a "Sound Fiscal Policy", Public Choice, forthcoming.

[25] Huber, G., M. Kocher and M. Sutter (2003), Government Strength, Power Dispersion in Governments and Budget Deficits in OECD-Countries: A Voting Power Approach, forthcoming in Public Choice.

[26] Martin, P. and C. A. Rogers (1997), Stabilization Policy, Learning by Doing and Economic Growth, Oxford Economic Papers 49, 152-166.

[27] OECD Economic Outlook (2001), Volume 2001/2, No. 70, December.

[28] Perotti, R. (1997), Fiscal Policy When Things are Going Badly, mimeo, Columbia University.

[29] Persson, T. and G. Tabellini (2000), Political Economics: Explaining Economic Policy, Cambridge, MA, MIT Press.

[30] Ramey, G. and V. Ramey (1995), Cross Country Evidence on the Link between Volatility and Growth, American Economic Review 85, 1138-1151.

[31] Rodrik, D. (1998), Why Do More Open Economies Have Bigger Governments?, Journal of Political Economy 106, 997-1032.

[32] Roubini, D. and J. Sachs (1989), Government Spending and Budget Deficits in the Industrialized Countries, Economic Policy 8, 99-132.

[33] Shapley, L. S. and M. Shubik (1954), A Method for Evaluating the Distribution of Power in a Committee System, American Political Science Review 48, 787-792.

[34] Slemrod, J. (1995), What Do Cross-Country Studies Teach About Government Involvement, Prosperity, and Economic Growth?, Brookings Papers on Economic Activity 2, 373-431. 
[35] Stiglitz, J. E. (1994), Endogenous Growth and Cycles, in: Shionoya, Y. and M. Perlman, eds: Innovation in Technology, Industries and Institutions, University of Michigan Press, 121-156.

[36] Van den Noord, P. (2000), The Size and Role of Automatic Fiscal Stabilizers in the 1990s and Beyond, OECD Working Paper, ECO/WKP 2000 (3). 
Table 1: GDP growth volatility and adjusted government size

\begin{tabular}{llll}
\hline \hline Variable & $\mathbf{( 1 )}$ & $\mathbf{( 2 )}$ & $\mathbf{( 3 )}$ \\
\hline GOV EXP & $-0.95(0.71)$ & $-2.68^{* * *}(1.01)$ & $-3.04^{* * *}(1.02)$ \\
\hline Observations & 72 & 72 & 72 \\
$R_{a d j}^{2}$ & 0.03 & 0.09 & 0.37 \\
\hline \hline
\end{tabular}

The dependent variable is the standard deviation of GDP growth rates in all specifications. White heteroskedasticity/serial correlation-corrected standard errors in parenthesis. Specification (3) includes only significant time dummies. ${ }^{* * *(* *)[*]}$ stands for $1 \%(5 \%)[10 \%]$ significant.

Table 2: GDP volatility, adjusted government size and controls

\begin{tabular}{ll}
\hline \hline Variable & OLS \\
\hline$G O V E X P$ & $-3.14^{* *}(1.39)$ \\
UNEMPL & $0.17^{* * *}(0.05)$ \\
VOLINFL & $0.24^{* *}(0.11)$ \\
GDPpc & $2.49^{*}(1.45)$ \\
\hline Observations & 72 \\
$R_{\text {adj }}^{2}$ & 0.66 \\
\hline \hline
\end{tabular}

The dependent variable is the standard deviation of GDP growth rates. White heteroskedasticity/serial correlation-corrected standard errors in parenthesis. The specification includes a two-way fixed effects error component. ${ }^{* * *}(* *)[*]$ stands for $1 \%(5 \%)[10 \%]$ significant.

Table 3: Instruments for government size

\begin{tabular}{lllll}
\hline \hline Variable & $\mathbf{( 1 )}$ & $\mathbf{( 2 )}$ & $\mathbf{( 3 )}$ & $\mathbf{( 4 )}$ \\
\hline GDPpc & $0.33^{* * *}(0.06)$ & $0.33^{* * *}(0.06)$ & $0.37^{* * *}(0.06)$ & $0.36^{* * *}(0.06)$ \\
UNEMPL & $0.02^{* * *}(0.00)$ & $0.02^{* * *}(0.00)$ & $0.02^{* * *}(0.00)$ & $0.02^{* * *}(0.00)$ \\
OPEN & $-0.003^{* * *}(0.00)$ & $-0.003^{* * *}(0.00)$ & $-0.004^{* * *}(0.00)$ & $-0.004^{* * *}(0.00)$ \\
IPDEBT & $0.05^{* *}(0.02)$ & $0.05^{* *}(0.02)$ & $0.04^{* *}(0.02)$ & $0.04^{* *}(0.02)$ \\
STRENGTH & & $0.06^{*}(0.03)$ & $0.06^{*}(0.03)$ & $0.07^{*}(0.03)$ \\
ELECTIONS & & $0.02(0.01)$ & $0.01(0.01)$ & \\
POP & & & $-0.06^{* *}(0.02)$ & $-0.06^{* *}(0.02)$ \\
\hline Observations & 72 & 72 & 72 & 72 \\
$R_{a d j}^{2}$ & 0.93 & 0.94 & 0.94 & 0.94 \\
\hline \hline
\end{tabular}

The dependent variable is the log of government expenditure in all specifications. White heteroskedasticity/serial correlation-corrected standard errors in parenthesis.Country-specific fixed effects are assumed in the specification. ${ }^{* * *(* *)[*]}$ stands for $1 \%(5 \%)[10 \%]$ significant. 
Table 4: GDP volatility and adjusted government size: IV Estimation

\begin{tabular}{lll}
\hline \hline Variable & OLS & IV \\
\hline$G O V E X P$ & $-3.14^{* *}(1.39)$ & $-2.94(1.93)$ \\
UNEMPL & $0.17^{* * *}(0.05)$ & $0.17^{* * *}(0.05)$ \\
VOLINFL & $0.24^{* *}(0.11)$ & $0.24^{* * *}(0.07)$ \\
GDPpc & $2.49^{*}(1.45)$ & $2.47^{*}(1.54)$ \\
\hline Observations & 72 & 72 \\
$R_{a d j}^{2}$ & 0.66 & 0.66 \\
\hline \hline
\end{tabular}

The dependent variable is the standard deviation of GDP growth rates in all specifications. The column labelled IV shows the estimates using instrumental variables. Instruments used: openness, interest payments on debt, government strength, population. Two-way fixed effects error component. ${ }^{* * *(* *)[*]}$ stands for $1 \%(5 \%)[10 \%]$ significant.

Table 5: GDP volatility and adjusted government size: quadratic model

\begin{tabular}{lll}
\hline \hline Variable & $\mathbf{( 1 )}$ & $\mathbf{( 2 )}$ \\
\hline GOVEXP & $-2.94(1.93)$ & $-36.57^{* *}(16.74)$ \\
GOVEXP & & $5.03^{* *}(2.47)$ \\
UNEMPL & $0.17^{* * *}(0.05)$ & $0.19^{* * *}(0.05)$ \\
VOLINFL & $0.24^{* * *}(0.07)$ & $0.21^{* * *}(0.07)$ \\
GDPpc & $2.47^{*}(1.54)$ & $2.84^{*}(1.46)$ \\
\hline Observations & 72 & 72 \\
$R_{a d j}^{2}$ & 0.66 & 0.69 \\
\hline \hline
\end{tabular}

The dependent variable is the standard deviation of GDP growth rates in all specifications. Instruments used: openness, interest payments on debt, government strength, population. Two-way fixed effects error component. ${ }^{* * *(* *)[*]}$ stands for $1 \%(5 \%)[10 \%]$ significant. 
Table 6: GDP volatility and different measures for government size: subcomponents

\begin{tabular}{|c|c|c|}
\hline & 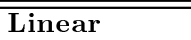 & Nonlinear \\
\hline GOVCONSnw & $-4.28(2.70)$ & $-13.01^{* * *}(4.37)$ \\
\hline GOVCONSnw ${ }^{2}$ & & $3.17^{* *}(1.34)$ \\
\hline GOVCONSw & $-4.31^{* *}(1.72)$ & $-19.91(15.83)$ \\
\hline GOVCONSw $w^{2}$ & & $3.14(3.33)$ \\
\hline$I N V E S T$ & $-0.94(0.66)$ & $-5.93(5.60)$ \\
\hline$I N V E S T^{2}$ & & $2.51(2.69)$ \\
\hline$S U B S I D$ & $0.56(1.12)$ & $-0.40(0.47)$ \\
\hline$S U B S I D^{2}$ & & $-0.84(0.54)$ \\
\hline SOCSEC & $-4.49(2.93)$ & $-7.13(11.11)$ \\
\hline$S O C S E C^{2}$ & & $0.98(2.31)$ \\
\hline$T R A N S$ & $0.21(0.86)$ & $-4.01(4.51)$ \\
\hline$T R A N S^{2}$ & & $0.81(0.84)$ \\
\hline$T A X d i r$ & $-0.26(0.73)$ & $-6.49^{* *}(2.81)$ \\
\hline$T A X d i r^{2}$ & & $1.43^{*}(0.73)$ \\
\hline TAXindir & $-2.81^{* *}(1.24)$ & $8.80(24.38)$ \\
\hline TAXindir ${ }^{2}$ & & $-2.21(5.17)$ \\
\hline$R E V E N$ & $-2.37(1.53)$ & $-36.43^{* *}(16.61)$ \\
\hline$R E V E N^{2}$ & & $5.01^{* *}(2.46)$ \\
\hline
\end{tabular}

The dependent variable is the standard deviation of GDP growth rates in all specifications. Instruments used: openness, interest payments on debt, government strength, population. Two-way fixed effects error component. ${ }^{* * *(*)}[*]$ stands for $1 \%(5 \%)$ [10\%] significant. 


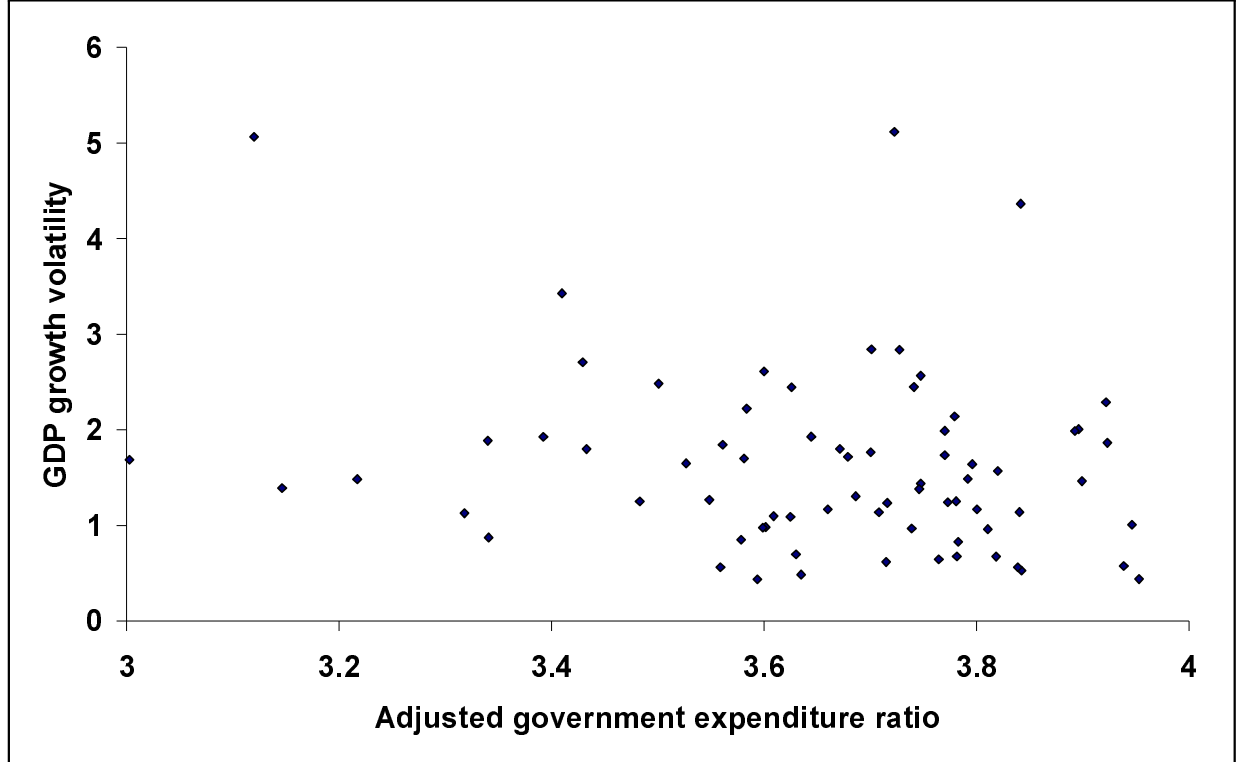

Figure 1: Adjusted government expenditure ratio versus GDP growth volatility: EU-15 countries (except Luxembourg) 1970-1999. 


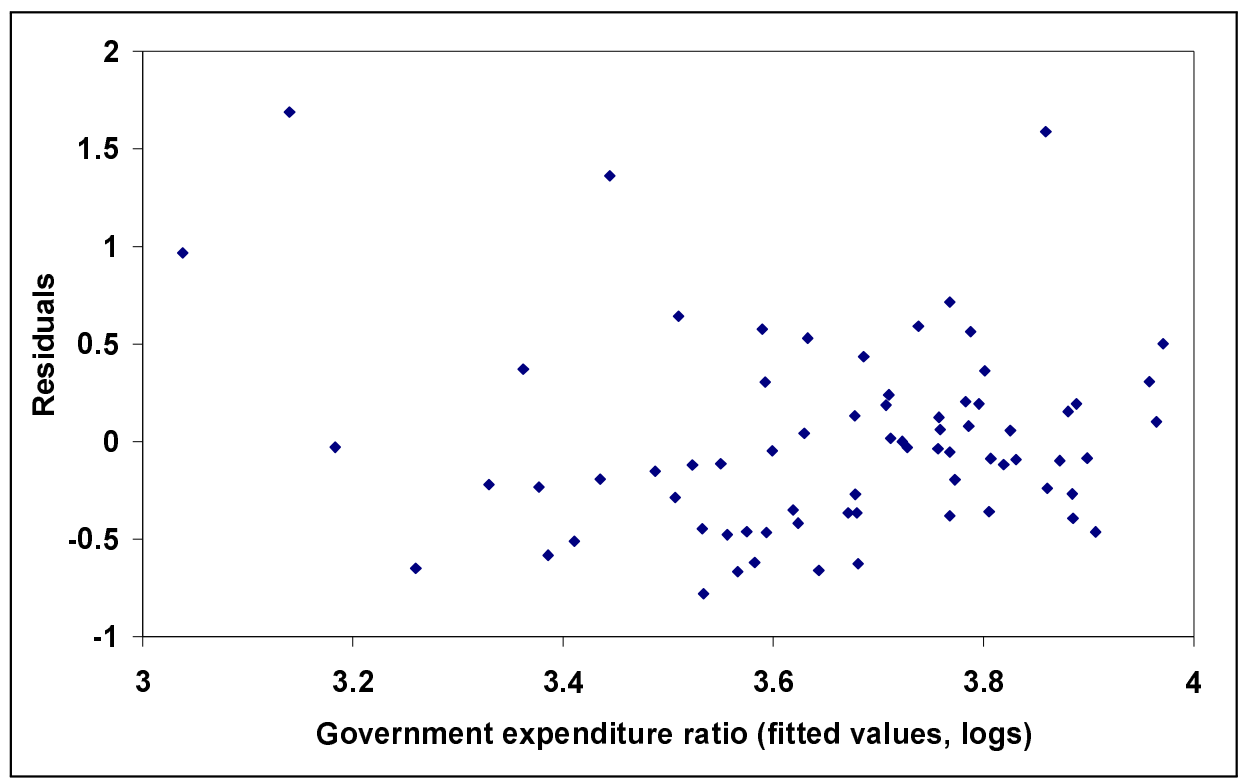

Figure 2: Residuals equation (4) versus fitted value of government expenditure ratio

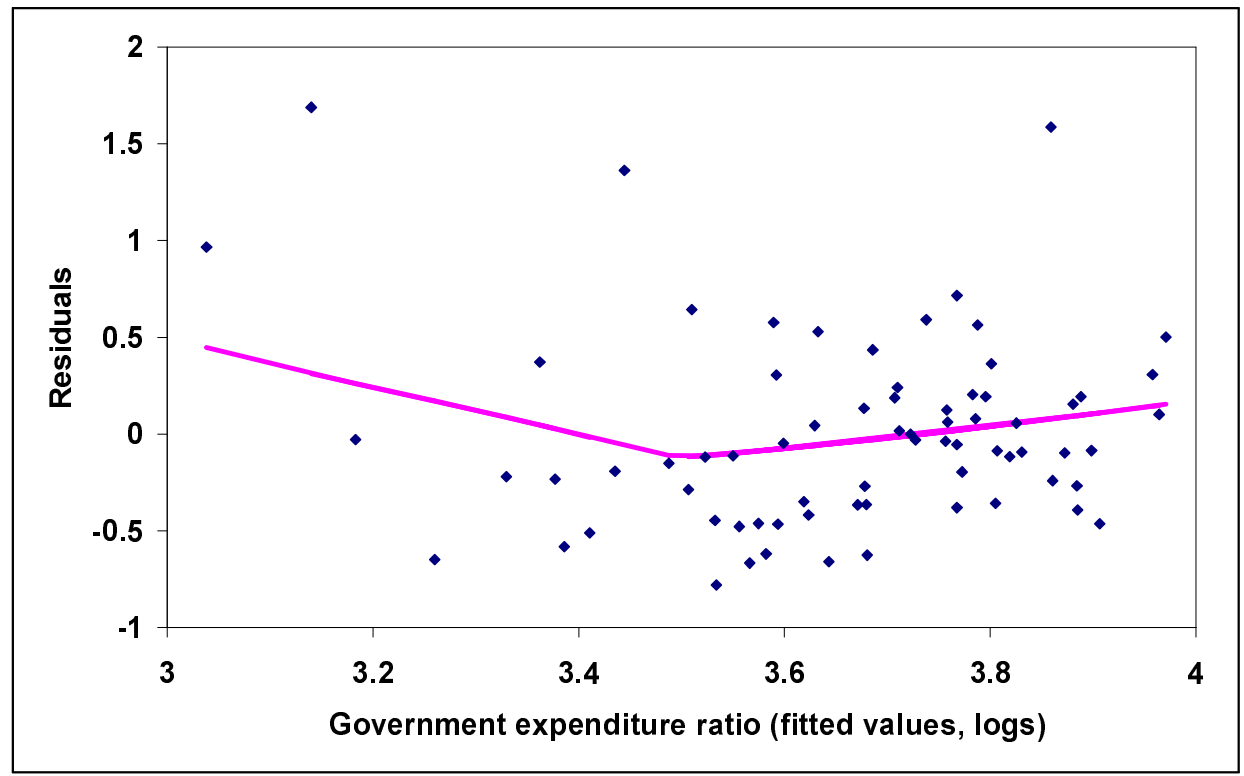

Figure 3: The Nearest Neighbor Fit curve 